\title{
Effect of RF Power on SnO Thin Films Obtained by Sputtering
}

\author{
Joseph Um, Byeong-Min Roh*, Sungdong Kim**, and Sarah Eunkyung Kim ${ }^{\dagger}$ \\ Graduate School of NID Fusion Technology, Seoul National University of Science and Technology, Seoul 139-743, Korea \\ *Department of Industrial and Information Systems Engineering, Seoul National University of Science and Technology, Seoul 139-743, Korea \\ **Department of Mechanical System and Design Engineering, Seoul National University of Science and Technology, Seoul 139-743, Korea \\ (Received July 12, 2012; Revised September 15, 2012; Accepted September 28, 2012)

\section{스퍼터링에 의해 제조된 $\mathrm{SnO}$ 박막의 RF 파워에 따른 특성 연구 \\ 엄요셉 · 노병민* · 김성동** · 김사라은경 ${ }^{\dagger}$ \\ 서울과학기술대학교 NID융합기술대학원 \\ *서울과학기술대학교 글로벌융합산업공학과 \\ **서울과학기술대학교 기계시스템디자인공학과 \\ (2012년 7월 12일 접수 ; 2012년 9월 15일 수정 ; 2012년 9월 28일 채택)}

\begin{abstract}
$\mathrm{SnO}$ thin films were fabricated by rf reactive sputtering on borosilicate substrates with an $\mathrm{Sn}$ target and $\mathrm{Ar} / \mathrm{O}_{2}$ gas mixture. The effect of rf power on the structural, electrical, and optical properties of SnO thin films was investigated with XRD, AFM, SEM, Hall effect measurements, and UV-Vis spectrometer. As a plasma power increased the crystallinity with a preferred orientation of SnO thin films was improved and the grain size slightly increased. However the grains were coalesced and excessively irregular in shape. The electrical conductivity of $\mathrm{SnO}$ thin films demonstrated a relatively low p-type conductivity of $0.024(\mathrm{Wcm})^{-1}$ at a higher power condition. Lastly, SnO thin films had poor optical transmittance in the visible range as a plasma power increased.
\end{abstract}

Key words : Thin films, Density, Conductivity, Tin compounds

\section{1. 서 론}

산화주석(tin oxide)의 경우 화학적으로 안정하고 $3.6 \mathrm{eV}$ 의 넓은 밴드 갭 에너지를 가지고 있는 $\mathrm{SnO}_{2}$ 가 일반적이 며, $\mathrm{SnO}_{2}$ 는 $n$ 형 반도체 특성을 띠고 있고 디스플레이용 투명전극, 태양전지, 가스센서 등에서 연구가 활발히 진 행되고 있다. ${ }^{1-6)}$ 반면 $\mathrm{SnO}$ 는 $2.7 \sim 3.4 \mathrm{eV}$ 의 밴드 갭 에너 지를 가지며 $p$ 형 반도체 특성을 띠고 있지만 화학적으로 준안정(metastable)한 상태로 알려져 있어 연구가 부진했 으나, 최근 TFT(thin film transistor)와 같은 투명 소자 응 용으로 많은 관심을 받고 있다. ${ }^{7)} P$ 형 산화물반도체의 경 우 도핑된 $\mathrm{Cu}$ oxide 나 $\mathrm{Zn}$ oxide 연구가 진행되어 왔으 며, ${ }^{8-10)} \mathrm{Sn}$ oxide의 경우에는 $n$ 형 $\mathrm{SnO}_{2}$ 에 $\mathrm{Sb}, \mathrm{In}, \mathrm{Mn}$, $\mathrm{Al}, \mathrm{Zn}$ 등을 도핑하는 연구는 있었으나, ${ }^{11-15)} p$ 형 $\mathrm{SnO}$ 연 구는 매우 부진한 상태이다. ${ }^{16-19)} P$ 형 $\mathrm{SnO}$ 는 도핑을 하여 야 $p$ 형 특성을 가지는 $\mathrm{SnO}_{2}$ 와 달리 도핑없이 박막 자체

\footnotetext{
${ }^{\dagger}$ Corresponding author : Sarah Eunkyung Kim

E-mail : eunkyung@seoultech.ac.kr

Tel : +82-2-970-6599 Fax : +82-2-944-6026
}

가 $p$ 형을 가지고 있기 때문에 공정이 용이하고, $n$ 형 $\mathrm{SnO}_{2}$ 박막과 함께 단종접합 pn 다이오드 (homojunction pn diode)를 만들 수 있는 장점이 있다. 또한, $\mathrm{SnO}$ 박막은 최 고가전자대(VBM: valence band maxima)에 존재하는 $\mathrm{Sn}$ $5 \mathrm{~s}$ orbital 구조 때문에 도핑한 $\mathrm{SnO}_{2}, \mathrm{ZnO}, \mathrm{NiO}$ 등의 박 막보다 전기전도도가 높은 $\mathrm{p}$ 형 반도체를 만들 수 있다고 알려져 있다. ${ }^{17,19)}$

산화주석박막을 증착방법 중 스퍼터링(sputtering)방법은 비교적 높은 증착속도, 대량생산 호환성, 두께 균일도, 확 장성(scalability) 등의 장점으로 인하여 널리 이용되고 있 다. ${ }^{20)}$ 일반적으로 스퍼터링 방법은 화학증기증착법(chemical vapor deposition)으로 증착된 박막에 비하여 박막의 균질 성, 재현성 및 표면의 구조(morphology) 등에서 우수한 것 으로 평가되고, 화학조성(chemical composition)과 박막 성 질의 조절이 쉬운 금속 타겟과 화학량(stoichiometry) 조절 이 용이한 산화물 타겟을 모두 사용할 수 있어 특성이 다 른 박막 공정으로 보고되어 있다. ${ }^{20,21)}$ 더욱이 스퍼터링 방 법은 가스분압, 압력, 파워, 온도, 등 공정 변수들을 변화 하여 박막의 특성을 쉽게 조절할 수 있다. $\mathrm{Lu}$ 에 의하면 
반응성 스퍼터링을 이용해 증착한 $\mathrm{ZnO}$ 의 경우 플라즈마 파워가 증가할수록 플라즈마내 $\mathrm{Ar}$ 이온 생성이 증가하여 $\mathrm{ZnO}$ 증착속도는 높아졌고, 증가된 이온에 의해 $\mathrm{Zn}$ 원자 가 많아지고, 기판(substrate)에 더 많은 핵(nuclei)이 생성 되어 표면의 구조는 조밀해졌고 결정립(grain) 사이즈는 줄었다고 하였다. 또한 플라즈마 파워가 증가할수록 우선 성장 방향(preferred orientation)을 강하게 가지는 결정구조 (crystalline)가 형성된다고 하였다. ${ }^{22}$ 반면 Hamzaoui에 의하 면 $\mathrm{SnO}_{2}$ 산화물 타겟을 이용한 스퍼터링으로 증착된 $\mathrm{SnO}_{2}$ 의 경우 플라즈마 파워가 높아질수록 결정립 사이즈가 증 가함을 보고하였다. ${ }^{23)}$ 또한 $\mathrm{RF}$ 파워가 증가할수록 높은 에너지를 가진 원자들에 의한 결함(defect)이 많이 발생하 여 박막의 투과도가 떨어짐을 설명하였다. 스퍼터링 조건 에 따른 박막의 물성 변화가 매우 큼을 알 수 있다.

본 연구에서는 반응성 스퍼터링 방법을 이용하여 $p$ 형 $\mathrm{SnO}$ 박막을 증착하였으며, 가스 유량, 온도, 압력을 고정 한 조건에서 플라즈마 파워를 변화시켜 파워에 대한 $\mathrm{SnO}$ 박막의 구조적, 전기적, 광학적 특성 변화를 연구하였다

\section{2. 실험 방법}

시편 $\left(20 \times 20 \mathrm{~mm}^{2}\right)$ 은 불규산(borosilicate) 유리와 실리콘 웨이퍼의 두 가지 기판을 사용하였고, $\mathrm{Sn}$ 타겟(99.99\%)과 $\mathrm{Ar}$ 과 $\mathrm{O}_{2}$ 가스를 혼합하여 반응성 스퍼터링으로 제작하였 다. 공정 압력, 가스 유량, 그리고 온도는 고정하고, 플라 즈마 파워를 200 500 W로 변화시켜 실험을 진행하였다. 증착 속도(deposition rate)는 플라즈마 파워가 증가할수록 $4,4 \AA / \mathrm{sec}$ 에서 $13.9 \AA / \mathrm{sec}$ 로 증가하였다. Table 1 에 각 시 편의 공정 변수들을 설명하였다. 공정 조건별 시편의 밀 도 변화량의 동향을 측정하기 위해서 질량과 부피를 다 음과 같이 측정하였다. 질량은 박막 증착 전후로 전자저 울(소수점 4자리)로 측정하여 계산하였고, 부피는 삼차원 측정기(3D profiler: Dektak 150, Vecco)로 측정한 박막의 두께와 사각형 새도 마스크(shadow mask)를 사용해 증착 한 박막의 면적을 이용하여 계산하였다. 제작된 시편들의 구조적 분석을 위해서 X선 회절계(XRD: ATX-G Rigaku)와 atomic force microscopy(AFM: Dimension 3100, Vecco)를 이용하여 박막의 결정구조, 우선 성장 방향, 표면거칠기를 확인하였고, 미세구조는 전계방출주사현미경(FE-SEM: $\mathrm{JSM}-7600 \mathrm{~F}, \mathrm{JEOL}$ )으로 관찰하였다. 광학적 분석을 위해
선 UV-Vis 분광계(Lamda 35, PerkinElmer)를 이용하여 각 시편의 투과도를 측정하였다. 박막 특성 분석을 위해서는 약 $2000 \AA$ 두께의 박막을 유리기판에 증착하였고, 밀도 계산을 위해서는 $1 \mu \mathrm{m}$ 두께의 박막을 실리콘 기판에 증 착하였다. 마지막으로 전기적 분석으로 홀 효과 측정 시 스템(HEMS: HMS-3000 Ecopia, 5500G magnetic field)을 이용하여 각 시편의 전기전도도(electrical conductivity), 캐 리어 농도(carrier concentration), 그리고 이동도(mobility)를 측정하였다. 홀 측정을 위해선 주석( $(\mathrm{Sn})$ 을 전극으로 사용 하였다.

\section{3. 결과 및 고찰}

Fig. 1 의 XRD 분석 결과에서 확인할 수 있듯이 플라즈 마 파워가 증가할수록 $\mathrm{SnO}$ 박막의 우선 성장 방향 (preferred orientation)이 강해졌고, 우선 성장 방향에 대한 결정면간 거리(d-spacing)은 감소하였으며, 결정립 크기는 증가하였다. XRD 데이터에 의거하여 결정면간 거리은 Bragg's law에 의해 계산되었으며 결정립 크기는 해당 픽 (peak)의 반가폭(FWHM, Full Width at Half Maximum) 을 이용한 Scherrer의 방법을 이용하여 계산하였다. ${ }^{24)}$ $200 \mathrm{~W}$ 의 경우 (101) 픽이 넓고 강도(intensity)가 낮은 구 조를 보여서 XRD 데이터에 의한 결정립 크기는 계산하 지 않았으나, Fig. 2 SEM 미세구조 사진에 의해서 $200 \mathrm{~W}$ 인 경우 결정립이 가장 작은 것으로 나타났으며, 결정립

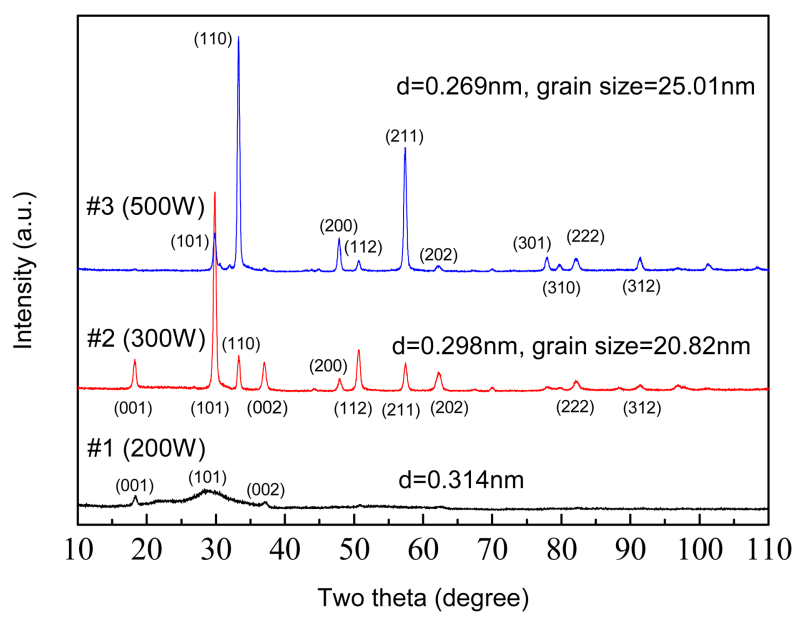

Fig. 1. X-ray diffraction patterns of $\mathrm{SnO}$ thin films.

Table 1. DepositioN Condition of Tin Oxide Thin Films

\begin{tabular}{cccccccc}
\hline Sample \# & $\begin{array}{c}\mathrm{O}_{2} \text { flow } \\
(\mathrm{sccm})\end{array}$ & $\begin{array}{c}\text { Ar flow } \\
(\mathrm{sccm})\end{array}$ & $\begin{array}{c}\text { Pressure } \\
(\mathrm{Pa})\end{array}$ & $\begin{array}{c}\text { Sub. Temp. } \\
\left({ }^{\circ} \mathrm{C}\right)\end{array}$ & $\begin{array}{c}\text { Power } \\
(\mathrm{W})\end{array}$ & $\begin{array}{c}\text { Deposition Rate } \\
(\AA / \mathrm{sec})\end{array}$ & $\begin{array}{c}\text { Density estimated } \\
\left(\mathrm{g} / \mathrm{mm}^{3}\right)\end{array}$ \\
\hline 1 & 9 & 61 & 0.67 & 300 & 200 & 4.394 & 1.4801 \\
2 & 9 & 61 & 0.67 & 300 & 300 & 7.03 & 1.8512 \\
3 & 9 & 61 & 0.67 & 300 & 500 & 13.945 & 3.7312 \\
\hline
\end{tabular}




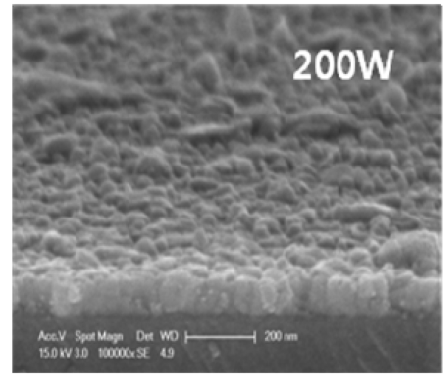

(a)

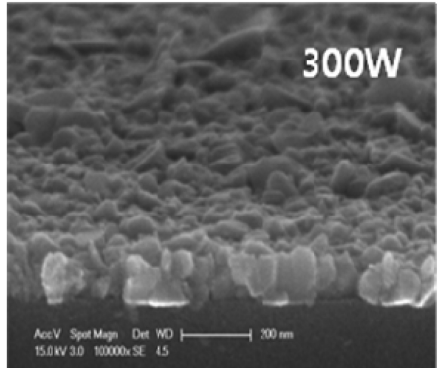

(b)

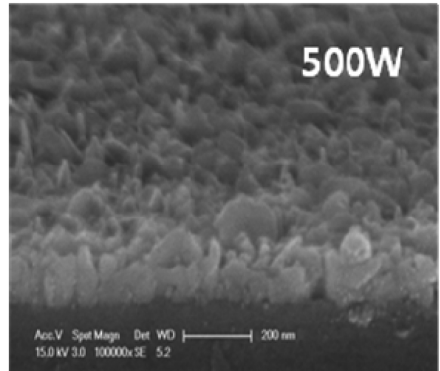

(c)

Fig. 2. SEM images of SnO thin films, (a) $200 \mathrm{~W}$, (b) $300 \mathrm{~W}$, and (c) $500 \mathrm{~W}$.

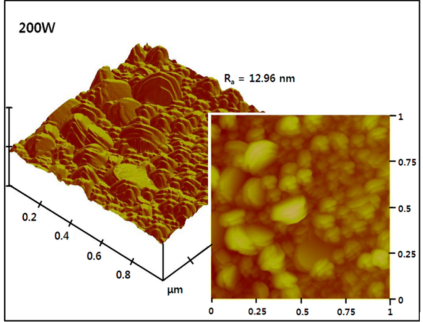

(a)

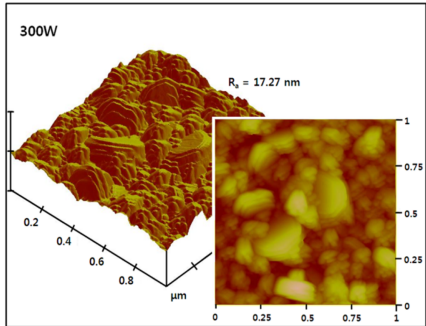

(b)

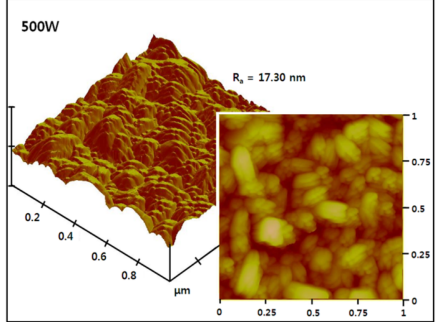

(c)

Fig. 3. AFM images of SnO thin films, (a) $200 \mathrm{~W}$, (b) $300 \mathrm{~W}$, and (c) $500 \mathrm{~W}$.

의 크기가 플라즈마 파워가 증가할수록 다소 증가하는 경 향을 확인할 수 있다. 플라즈마 파워가 증가할수록 결정 구조가 뚜렷하게 나타났으며, $300 \mathrm{~W}$ 에서는 (101) 픽이 우 선 성장 방향이었으나, $500 \mathrm{~W}$ 에서는 (101) 픽이 감소하고 상대적으로 (110) 픽이 증가하는 것을 볼 수 있다. 플라 즈마 파워가 증가할수록 우선 성장 방향을 강하게 가지 는 결정구조가 형성된다고 보고된 바 있고, ${ }^{22)}$ 이는 플라 즈마 파워가 증가할수록 산소와 아르곤이 $\mathrm{Sn}$ 타겟과 충 돌(bombardment)이 커져서 $\mathrm{Sn}$ 타겟 표면에 스퍼터된 $\mathrm{Sn}$ 분자(molecule)이 많아지고, 기판 표면에 도착하는 $\mathrm{Sn}$ 의 kinetic energy도 증가하기 때문이다. ${ }^{25)}$ 그래서 플라즈마 파워가 증가할수록 표면은 거칠어지고 삼차원적으로 자 라는 경향을 보이며, 결정성도 좋아진다. 또한, 플라즈마 파워가 증가함에 따라 결정방향이 바뀌었으며 결정면간 거리의 감소는 박막의 미세구조 변화의 한 요인으로 볼 수 있다. Fig. 3은 표면 거칠기를 AFM으로 관찰한 사진 이다. 박막의 표면거칠기(roughness, $\mathrm{R}_{\mathrm{a}}$ )는 다소 증가하는 경향을 보였고 매우 불규칙한 미세구조를 볼 수 있다. 이 는 플라즈마 파워가 증가할수록 핵 성장이 활발하게 이 루어지고, 산화주석박막 내 원자들의 확산 또한 활발해짐 에 따라서 결정성이 향상된 것으로 사료된다. 하지만 $\mathrm{AFM}$ 분석 결과를 보면 표면의 수직 상승과 같은 아주 불규칙 한 형태를 보이고 있고, 특히 특정방향의 결정립에 응집 (coalesce)된 것과 같은 형태를 나타내기 때문에, 이는 시 편 내에 전체적인 표면 높낮이에 차이가 생긴 것으로 사 료된다. 결정들의 불규칙하고 응집되어있는 형태로 인해 $\mathrm{AFM}$ 결과로 결정립 크기는 계산 하지 않았으며, 앞에서
설명한 것과 같이 결정립 변화에 대해서는 평균값을 주 는 XRD 결과로 분석하고 $\mathrm{SEM}$ 사진과 비교하였다.

Table 1에 나타낸 것과 같이 플라즈마 파워가 증가할수 록 $\mathrm{SnO}$ 박막의 밀도가 증가하는 경향을 보였다. 이는 플 라즈마 파워가 증가할수록 조밀면과 응집된 결정립을 가 진 박막형성에 의한 것으로 사료된다. 본 실험에서는 박 막의 밀도를 정량적 방법으로 측정한 것이 아니라 후막 의 밀도 측정 계산방법으로 진행하였으며, 플라즈마 파워 에 의한 밀도의 증감 동향만을 확인하는데 이용하였다. 일 반적으로 밀도가 증가할 때 전자흡수(electronic absorption) 특성변화 때문에 분극성(polarizability)이 감소하고, ${ }^{28)}$ 이는 박막의 굴절률(refractive index), 전기전도도(electrical conductivity), 광학적 성질에 영향을 미친다. Lorentz-Lorenz 공식이 나 Drude 공식과 같은 굴절률과 밀도의 관계식을 나타내는 공식에서 보듯이 밀도가 증가하면 일반적으로 굴절률이 비선형으로 비례 증가한다. ${ }^{28,29)}$ 그리고 굴절률이 증가할 수록 광흡수단(optical abruption edge)은 파장(wavelength) 이 긴 방향으로, 즉 광학적 밴드 갭(optical band gap)이 낮은 방향으로 이동한다. ${ }^{30)}$ 본 실험에서 제조된 $\mathrm{SnO}$ 박 막의 경우 Fig. 4에 나타난 것과 같이 플라즈마 파워가 증가할수록 광흡수단이 긴 파장 방향으로 이동하였으며, 이는 박막 내에 존재하는 $\mathrm{Sn}$ 빈자리(vacancy)가 플라즈마 파워가 증가할수록 많아져서 구조적 결함을 생성했기 때문 이라 사료된다. ${ }^{7)}$ 또한 $\mathrm{SnO}_{2}$ 박막은 가시광 영역에서 85$90 \%$ 의 투과도를 가지고 있으나, ${ }^{26,27)}$ 제작된 $\mathrm{SnO}$ 박막은 가 시광영역에서의 투과도가 매우 낮았으며, 플라즈마 파워 가 증가할수록 투과도는 $60-70 \%$ 에서 $40-50 \%$ 로 낮아짐을 


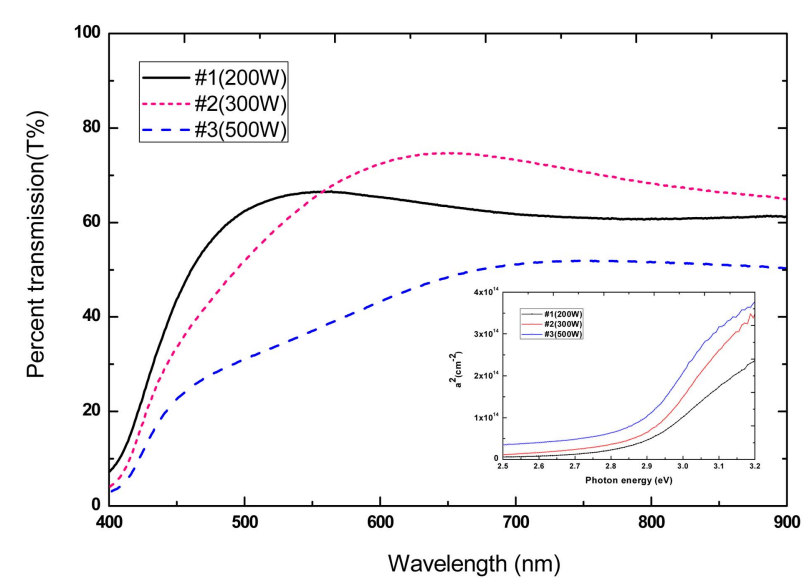

Fig. 4. Optical properties of $\mathrm{SnO}$ thin films.

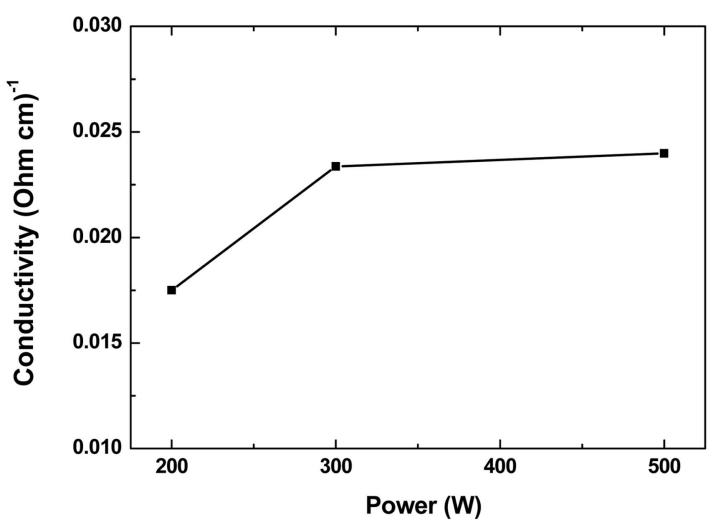

(a)

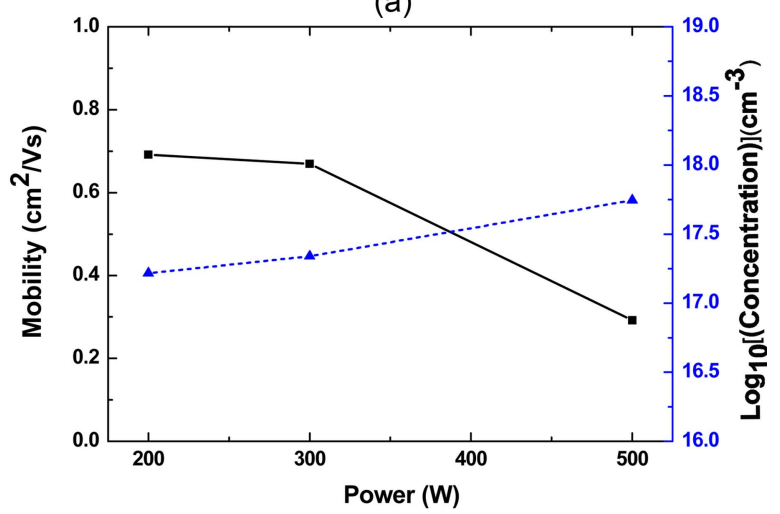

(b)

Fig. 5. Electrical properties of $\mathrm{SnO}$ thin films, (a) Electrical Conductivity and (b) Mobility and Carrier Concentration.

보였다. 일반적으로 $\mathrm{SnO}$ 는 $\mathrm{SnO}_{2}$ 보다 산소 비율이 적고 굴절률이 낮아 투과도가 낮게 나타나고, 화학조성, 결정 립 크기, 구조적 결함 등 또한 투과도 특성에 영향을 미 친다. ${ }^{18,19)}$ 플라즈마 파워가 증가할수록 높은 에너지를 가 진 원자들이 많아지고 $\mathrm{Sn}$ 빈자리가 많아지면서 구조적 결 함을 생성하였고, 결정립 크기는 커졌으며, 표면거칠기도 높아지면서 투과도가 점점 낮아지는 것으로 사료된다.

마지막으로 약 $500 \mathrm{~nm}$ 두께의 $\mathrm{Sn}$ 전극을 증착하여 전
기적 특성을 살펴보았다. 측정 시 팁 접촉에 의한 전극 손 상은 나타나지 않았으며, 또한 $\mathrm{Sn}$ 전극은 시편과 오믹(ohmic) 접촉을 하고 있어 전기적 특성 파악에 큰 영향을 미치지 않았다. 홀 측정을 통해 각 시편들의 전기적 특성을 측정 할 수 있었으며, 이들의 결과를 Fig. 5에 나타내었다. 홀 측 정 결과 모든 시편은 $\mathrm{p}$ 형 전도 형태(conduction type)를 나 타내었고, 전기전도도는 $0.017(\Omega \mathrm{cm})^{-1}$ 에서 $0.024(\Omega \mathrm{cm})^{-1}$ 로 선행연구들과 비슷한 값을 보였다. ${ }^{11,12,17-19,31)}$ 하지만 $\mathrm{SnO}_{2}$ 박막에 도핑하여 만든 $\mathrm{p}$ 형 $\mathrm{SnO}_{2}$ 박막보다는 다소 낮은 값을 띄고 있다. ${ }^{11)}$ 플라즈마 파워가 증가할수록 $\mathrm{Sn}$ 빈자 리가 생성되었고, ${ }^{7)}$ 이는 소폭 증가한 케리어 농도에 영향 을 주었다. $\mathrm{SEM}$ 과 $\mathrm{AFM}$ 측정 결과에서 보듯이 $\mathrm{SnO}$ 박 막은 기둥(column)형식으로 불규칙한 결정립 구조를 나타 내고 있으며, 이는 이동도 감소에 영향을 미친 것으로 생 각된다.

\section{4. 결 론}

$\mathrm{RF}$ 반응성 스퍼터링 방법을 이용하여 $\mathrm{SnO}$ 산화주석박 막을 증착하였고, $\mathrm{XRD}, \mathrm{AFM}, \mathrm{UV}-\mathrm{Vis}$ 분광계 및 홀 측정 을 통하여 박막의 특성을 분석하였다. 본 연구는 플라즈 마 파워에 의한 $\mathrm{SnO}$ 박막의 구조적, 광학적, 전기적 특성 변화를 고찰하는데 중점을 두었다. 플라즈마 파워가 증가 할수록 $\mathrm{SnO}$ 박막은 우선 성장 방향이 강해졌고, 우선 성 장 방향에 대한 d-spacing은 감소하였으며, 결정립 크기는 증가하였다. 또한 매우 불규칙한 미세구조를 보였다. 플 라즈마 파워가 증가할수록 박막 내에 존재하는 결함이 많 아져서 $\mathrm{SnO}$ 박막의 광흡수단은 긴 파장 방향으로 이동하 였고 투과도는 낮아짐을 보였다. 그리고 캐리어 농도의 증가에 의해서 전기전도도가 소폭 증가하였다.

\section{Acknowledgment}

이 논문은 2012년도 정부(교육과학기술부)의 재원으로 한국연구재단의 지원을 받아 수행된 기초연구사업임 (No. 2012-0003724).

\section{REFERENCES}

1. M. Batzill and U. Diebold, "The Surface and Materials Science of Tin Oxide," Prog. Surf. Sci., 79 47-154 (2005).

2. B. G. Lewis and D.C. Paine, "Applications and Processing of Transparent Conducting Oxides," MRS Bull., 25 [8] 22-7 (2000).

3. J. Kim, B. Kim, S. Choi, J. Park, and J. Park, " $\mathrm{SnO}_{2}$ Semiconducting Nanowires Network and Its $\mathrm{NO}_{2}$ Gas Sensor Application (in Korean)," Kor. J. Mater. Res., 20 [4] 223-27 (2010).

4. S. E. Kim and M. Oliver, "Structural, Electrical, and Optical 
Properties of Reactively Sputtered $\mathrm{SnO}_{2}$ Thin Films," Met . Mater. Int., 16 [3] 441-46 (2010).

5. S. P. Kim, Y. Kim, S. D. Kim, and S. E. Kim, "The Effect of Vacuum Annealing of Tin Oxide Thin Films Obtained by RF Sputtering," J. Kor. Ceram. Soc., 48 [4] 316-22 (2011).

6. H. D. Kim, J. S. Choi, and D. W. Shin, "Fabrication of the Conductive Fiber Coated Sb-doped $\mathrm{SnO}_{2}$ Layer," J. Kor. Ceram. Soc., 39 [4] 386-93 (2002).

7. W. Guo, L. Fu,Y. Zhang, K. Zhang, L. Y. Liang, Z. M. Liu, and H. T. Cao, "Microstructure, Optical, and Electrical Properties of p-type SnO Thin Films," Appl. Phys. Lett., 96 042113:1-3 (2010).

8. H. Kawazoe, M. Yasukawa, H. Hyodo, M. Kurita, H. Yanagi, and H. Hosono, "P-type Electrical Conduction in Transparent Thin Films of $\mathrm{CuAlO}_{2}$," Nature, 389 [6654] 939-42 (1997).

9. A. Kudo, H. Yanagi, H. Hosono, and H. Kawazoe, " $\mathrm{SrCu}_{2} \mathrm{O}_{2}$ : A $p$-type Conductive Oxide with Wide Band Gap," Appl. Phys. Lett., 73 [2] 220-22 (1998).

10. A. Tsukazaki, A. Ohtomo, T. Onuma, M. Ohtani, T. Makino, M. Sumiya, K. Ohtani, S.F. Chichibu, S. Fuke, Y. Segawa, H. Ohno, H. Koinuma, and M. Kawasaki, "Repeated Temperature Modulation Epitaxy for p-type Doping and LightEmitting Diode Based on ZnO," Nat. Mater. 4 [1] 42-6 (2005).

11. J. Ni, X. Zhao, X. Zheng, J. Zhao, and B. Liu, "Electrical, Structural, Photoluminescence and Optical Properties of ptype Conducting, Antimony-doped $\mathrm{SnO}_{2}$ Thin Films," Acta. Mater., 57 278-85 (2009).

12. Z. Ji, Z. He, Y. Song, K. Liu, and Z. Ye, "Fabrication and Characterization of Indium-doped p-type $\mathrm{SnO}_{2}$ Thin Films," J. Cryst. Growth, 259 282-85 (2005).

13. C. H. Lee, B. A. Nam, W. K. Choi, J. K. Lee, D. J. Choi, and Y. J. Oh, "Mn: $\mathrm{SnO}_{2}$ Ceramics as p-type Oxide Semiconductor," Mater. Lett., 65 722-25 (2011).

14. J. Ni, X. Zhao, and J. Zhao, "P-type Transparent Conducting $\mathrm{SnO}_{2}: \mathrm{Zn}$ Film Derived from Thermal Diffusion of $\mathrm{Zn} / \mathrm{SnO}_{2} /$ Zn Multilayer Thin Films," Surf. Coat. Tech., 206 [21] 4356-61 (2012).

15. J. Zhao X.J. Zhao, J.M. Ni, and H.Z. Tao, "Structural, Electrical and Optical Properties of p-type Transparent Conducting $\mathrm{SnO}_{2}$ :Al Film Derived from Thermal Diffusion of $\mathrm{Al} / \mathrm{SnO}_{2} / \mathrm{Al}$ Multilayer Thin Films," Acta Mater., 58 624348 (2010).

16. X.Q. Pan and L. Fu, "Oxidation and Phase Transitions of Epitaxial Tin Oxide Thin Films on (1012) Sapphire," $J$. Appl. Phys., 89 [11] 6048-55 (2001).

17. Y. Ogo, H. Hiramatsu, K. Nomura, H. Yanagi, T. Kamiya, M. Hirano, and H. Hosono, " $p$-channel Thin-Film Transistor using $p$-type Oxide Semiconductor, SnO," Appl. Phys. Lett., 93 032113:1-3 (2008).

18. L. Y. Liang, Z. M. Liu, H. T. Cao, Z. Yu, Y. Y. Shi, A. H.
Chen, H. Z. Zhang, Y. Q. Fang, and X. L. Sun, "Phase and Optical Characterizations of Annealed SnO Thin Films and Their p-Type TFT Application,” J. Electrochem. Soc., 157 [6] H598-H602 (2010).

19. L.Y. Liang, Z.M. Liu, H.T. Cao, and X.Q. Pan, "Microstructural, Optical, and Electrical Properties of SnO Thin Films Prepared on Quartz via a Two-Step Method," Appl. Mater. Int., 2 [4] 1060-65 (2010).

20. K. Ellmer, "Magnetron Sputtering of Transparent Conductive Zinc Oxide: Relation between the Sputtering Parameters and the Electronic Properties," J. Phys. D: Appl. Phys., 33 [4] R17-R32 (2000).

21. S. H. Park, J. H. Kang, and K. S. Yoo, "Fabrication of the $\mathrm{SnO}_{2}$ Thin Film Gas Sensors using an RF Magnetron Sputtering Method and Their Alcohol Gas-Sensing Characterization," J. Kor. Sens. Soc., 14 [2] 63-8 (2005).

22. Y.M. Lu, W.S. Hwang, W.Y. Liu, and J.S. Yang, "Effect of RF Power on Optical and Electrical Properties of ZnO Thin Film by Magnetron Sputtering," Mater. Chem. Phys., 72 269-72S (2001).

23. Hamzaoui and M. Adnane, "Effects of Temperature and r.f. Power Sputtering on Electrical and Optical Properties of $\mathrm{SnO}_{2}$," Appl. Energ., 65 19-28 (2000).

24. C. Suryanaraynara and M. G. Norton, X-ray diffraction -A Practical Approach; p.212, Plenum Press, New York, 1998.

25. D. Hwang, K. Bang, M. Jeong, and J. Myoung, "Effects of RF Power Variation on Properties of ZnO Thin Films and Electrical Properties of $\mathrm{p}-\mathrm{n}$ Homojunction," J. Cryst. Growth, 254 449-55 (2003).

26. V. V. Kissine, S. A. Voroshilov, and V. V. Sysoev, "Oxygen Flow Effect on Gas Sensitivity Properties of Tin Oxide Film Prepared by R.F. Sputtering," Sens. Actuat. B, 55 55-9 (1999).

27. I. H. Kim, J. H. Ko, D. Kim, K. S. Lee, T. S. Lee, J. Jeong, B. Cheong, Y. J. Baik, and W. M. Kim, "Scattering Mechanism of Transparent Conducting Tin Oxide Films Prepared by Magnetron Sputtering," Thin Solid Films, 515 2475-80 (2006).

28. K. Vedam and P. Limsuwan, "Piezo- and Elasto-Optic Properties of Liquids under High Pressure. II. Refractive Index vs Density," J. Chem. Phys., 69 [11] $4772-78$ (1978).

29. W. Rzodkiewicz and A. Pana, "Determination of the Analytical Relationship between Refractive Index and Density of $\mathrm{SiO}_{2}$ Layers," Acta Phys. Pol., 116 S92-S94 (2009).

30. E. Marquezy, J. M. Gonzalez-Lealy, R. Jimenez-Garayy, S. R Lukicz, and D. M. Petrovicz, "Refractive-Index Dispersion and the Optical-Absorption Edge of Wedge-Shaped Thin Films of $\mathrm{Cu}_{\mathrm{x}} \mathrm{As}_{50} \mathrm{Se}_{50 \mathrm{x}}$ Metal-Chalcogenide Glasses," J. Phys. D: Appl. Phys., 30 690-702 (1997).

31. Y. Kim, J. H. Jang, J. S. Kim, S. D. Kim, and S. E. Kim, "Nitrogen Doped p-type SnO Thin Films Deposited via Sputtering," Mater. Sci. Eng. B, 177 1470-75 (2012). 